\title{
Consultants rule OK? the changing pattern of medical hierarchy
}

\author{
N F Coghill formerly West Middlesex Hospital, Isleworth, Middlesex
}

\section{Editor's note}

Dr Coghill considers the changing role of the hospital consultant in British medicine. He emphasises the social nature of this role and suggests that management by coordinating and facilitating the participation of members of different disciplines is becoming an important attribute for today's consultants even though so far as patient care is concerned they must remain responsible for final decision-making. Consultants, he suggests, must also be partly responsible for the health of their hospitals not only because patient care in part depends on this but also because of their special awareness of the "physiology and pathology of the institution'. He suggests changing ways in which this responsibility may be met. He warns against the dangers of too narrow a professionalism and argues that it is becoming ' $a$ hallmark of the mature professional that he relates to wider contexts by getting outside his own patch'.

Traditionally consultants have been powerful people, in the sense that what they did at work and said in public had effects, sometimes profound, upon the work and lives of others, and resulted in financial cost to society. Their training, knowledge and skill have given them sapiential authority, reinforced by public acceptance of their role. Some doctors feel it is ironic that the influence they exert appears to be lessening at a time when standards in medicine have never been higher, and it is possible to do so much more for their patients than it was even a few years ago. It was awareness of this feeling that no doubt gave rise to the somewhat provocative title of the symposium arranged by the London Medical Group that is now the title of this paper.

I suggest that while it is inevitable that consultants' influence will be circumscribed in some traditional areas, they will get satisfactions from being able to make new contributions that are valuable to society and in the best interests of their patients. To understand how this may happen we must examine relevant aspects of consultants' and hospitals' work.

\section{Authority and authoritarianism}

We are partly concerned with the use, and abuse, of authority, and we should be clear about the difference between authority and authoritarianis The exercise of authority may be described $\rightarrow$ s behaviour actuated by knowledge, experienge, expertise (skill) and, it is to be hoped, some wisdem - 'sapiential authority'. Authoritarianism is behầiour in situations in which the person has no expett or special knowledge but is using his position, based upon other attributes, to try to influence events. $\infty$

Society needs technologists and professiomal people of high calibre to get things done and dotte well. It generally accepts the authority of $p$ 戛fessionals especially when it knows of the varied measures taken to ensure high standards of work. Nevertheless, as more people are better educatef, better off financially and more conscious of thefr 'rights', there is less automatic acceptance of professional actions and dicta. Consciousness of worth and rights, and increased expectations, 각e concomitants of a maturing society. Maturity be advanced by the development of awareness कृf duties and responsibilities by doctors no less than by everyone else. (I)

So doctors, like other specialists, will be questioned about their work, and there will be los tolerance of professionals who try, maybe for selfish reasons, to influence events outside the boundaries of their competence.

\section{Human relationships}

Rapid technological change is a striking feature $\frac{\circ}{\ominus f}$ the current medical scene, as it is elsewhere. technological 'progress' is faster than our ability to learn about its social uses and effects we are trouble. How may this adaptive process be accelatsated? Part of the answer lies in the enlargement of human relationships across a wide social spectrufn.

Attitudes to the status of different races axd classes, of different kinds of worker, of childrêg, and of the relation of men and women to eagh other, are slowly, and often painfully, undergoing change. The professions cannot escape these absorbing social trends. That medicine may more closely engaged than teaching or the law is a tribute to the liveliness, vigour and vision of ${ }^{\mathrm{Q}} \mathrm{s}$ practitioners. Many doctors are examining their relationships with others at work, not only professional colleagues; and particularly with the patients. 


\section{Constraints}

In their professional work doctors, and to a degree nurses, operate under two constraints:

I) In the care of patients, doctors' behaviour affects them, and their relatives and friends, in a variety of ways not always closely related to diagnosis and treatment. All 'clients' (including relatives) may feel the need for information about, and clarification of, the medical process. Doctors, like other professionals, must accept questioning and not mind if it is probing-about methods, treatment and management. There are many uncertainties, indeed unknowns, in medicine, but doctors derive support and protection, in what may sometimes seem to be a threatening process, from high standards of knowledge and practice that are secured through the roles of the profession's Royal Colleges, the Universities, and our national traditions of practice and research.

2) Professional people do their work in a working society and its performance has effects, sometimes considerable, upon others in that society. The consultant in outpatients does not work in a vacuum. What he does affects not only his patient and the relatives, but also those working with him, especially the nurses (and in both cases in ways he may not always immediately perceive). During a ward round a consultant may propose management of a patient that sister cannot carry out with the resources at her command. If the consultant is insistent because of his patient's state, he should at least become aware of what sister needs to carry out his prescription and help her to secure the necessary resources. $\mathrm{He}$ may also have to consider modifying his original plan and to negotiate. Such manoeuvres may be difficult unless there is mutual confidence and respect between consultant and sister, born of a system of perceptions and communications affecting not only themselves but all their staffs.

These two constraints may interact through involvement of patients and staff. Many of the troubles afflicting people who work in hospitals have been caused by the institution, especially in the case of nurses. (2) This may improve if the hospital community draws together under the external threat of dire financial stringency. Not for nothing have hospitals been labelled anxious workplaces. In reality the 'institution' is an abstraction, a term merely for all who work in it, so it is proper to make the onus personal to each member of staff.

\section{The changing culture of work}

A rather apocalyptic leader in the British medical journal (3) said that trade unions were undermining medical authority. This was probably true in only a few cases, and then mainly because of failure of management to be sufficiently participative. 'Management', however, is not only the administration. Thoughtless, imperceptive doctors and nurses may easily upset relationships in a hospital.

Nevertheless, some doctors are worried that people like engineers, porters and cleaners, and possibly politicians, may try to influence how they do their work. Certainly some 'industrial action' (including the doctors' own) has interfered with medical practice. Awareness by doctors of the effects of their actions upon the society within which they work should help to lessen this possibility. Porters, cleaners and engineers do important jobs and are worthy of consideration and appreciation, not often accorded by doctors. They want, like most who work, to be able to exert some influence control-over the events that shape their daily working lives. To provide a simple illustration: it was the practice at my hospital for junior doctors in the medical wards to send repeated 'emergency' specimens to the laboratory, a quarter of a mile away, during the night. Many were not so urgent that they could not have been grouped together and sent at less frequent intervals. The night porter made representations about this behaviour because it was interfering with his other duties. After discussion the medical staff modified their practices to the porters' satisfaction who felt that the society in which they worked had been responsive.

Some patients in special hospitals for the criminally insane have been denied the care and treatment prescribed for them because of actions by nurses and prison officers. It has been reported that consultants have been denied access to patients. (4) In so far as these actions, indefensible though they are, arise from grievances and fears of staff at work, it is reasonable to ask how supportive the consultants concerned have been in pressing for alleviation of unsatisfactory working and safety conditions.

Relationships may be strained when laboratories are asked to do tests, some of them difficult and time-consuming, and sometimes out of normal working hours, that are not all necessary. When technicians question these requests, if doctors are not prepared to justify them in discussion, heated arguments and recriminations may result that do not advance the patient's care. Respect, even for consultants, is no longer any kind of right, and must be earned. Everyone is asked occasionally to see patients unnecessarily, or to do tests or examinations that seem unlikely to be rewarding. Such problems, often arising from anxiety, are easily resolved when relationships within the hospital are considerate and supportive.

It is worth reminding junior colleagues that every case reference, every pathology and X-ray form despatched, is a request to a colleague to do some work on a patient who is not his. An interested and helpful response is more likely if forms are meticulously completed with all relevant data. 


\section{Participation}

This term has been unjustifiably derided, mainly because of disillusion with its practice. Properly it must imply mutual discussion of contributions by all staff, including administrators, in decision making, with in practice events affecting the workplace being modified. Contrary to popular belief this process need not take more time in total than traditional methods of management, but it does require that managers are fully committed to it and willing to derive work satisfaction from their coordinative and facilitative functions rather than their customary power base. The great advantage is that decisions are better, and more acceptable to those who will have to implement them, and future trouble is likely to be avoided. What relevance has this to consultants?

Much of patient management, depending as it does nowadays on help from different people in different disciplines, needs 'case discussion' to achieve the best care for the patient. Such discussion leads to learning by all involved in it, including the consultant. Participants learn from their own and others' experience under the imperatives of patient care. It is truly participative in that the discussion is a form of debate with participants' contributions influencing decisions.

There are wider reasons why consultants should understand and practise participation. It has been argued $(5,6)$ that doctors cannot escape all responsibility for the health of the hospital if only because their prime role, patient care, depends greatly on it, and because they are in a position to understand the physiology and pathology of the institution. The smooth running of that complex organisation depends on some degree of consultant involvement. A contribution will come from consultants' understanding of the needs of other staff to do their work properly, and of how their own work affects others. The value of the Divisional ('Cogwheel') system, and of the medical committee, in the development of good communications within the hospital, and of interprofessional involvement in decision making, has been shown. (7)

A participative style of management then, whether for doctor, nurse or administrator, is a means of gaining positive contributions to the work of individuals and of teams. The framework for its practice must include appropriate delegation of functions and duties. People should know what their job is and what is expected of them so that they recognise 'ownership' of their problems and have sufficient mandate to solve them or attempt to do so, and to show initiative. Revans, (6) in discussing his 'Principle of insufficient mandate', says: 'I have chosen the word "mandate" from a number of competitors, including "concern", "responsibility", "mission", "trust", "charge" and "involvement", as it implies, to me, not only what is specifically commanded to be done but also what ought to कe done over and above that for which specillc commands have been issued. Thus a group of managers striving to master a particular situation, but unable either, at the start, to identify it $\vec{\nexists}$ in terms of their own experience or, subsequenfly, to monitor the decisions they take about it, Gre seen to be handicapped by an insufficient mandate. They may lack information, feedback, power, a not seldom, motivation to act. In particular they must possess all of these in terms of changing themselves in the course of mastering the situation'.

Little of all this will be achieved without $\rightarrow$ an environment that encourages discussion of the nesed for change, particularly in attitudes, and of ers support not only for the delicate and sensitave feelings that will be exposed, but for those who hate to cope with the effects of change. Alterations $\overrightarrow{i n}$ ward routines, for example, suggested by doctorogr sister, are easier to inaugurate, and will probably work better, if their likely effects are first considered by all who may be involved in the including, where appropriate, patients, and moäified as a result of points raised in discussion. This is when staff may contribute from their experiefe of their own work, and of how others' work affects them. Such procedure is hardly a waste of time it results, as it commonly does, in more appropriagte action that is acceptable to all concerned. It fils other benefits. People are happier and work betger if their views are considered and maybe acted up and 'industrial action' is either prevented or easily controlled. It has been shown that in a respons iye hospital environment patients may stay for a mueh shorter time in the ward. (8)

\section{The team}

Teamwork has been decried. (9) But doctors work with many. professional colleagues and willy nity work in a team, which need not be narrowly defined, nor constrictive in practice. Providing a milieu for learning and action it offers a broadening and rewarding method of working. Many problems of patient care can be solved only by the use $\overline{\bar{N}} f$ regular or ad hoc team meetings. Furthermore, us it is difficult to conceive of an efficient hospital without consultants influencing its running, thesy must devote time to meetings of various kinds. ( Yet it is commonplace to hear doctors complain $f$ the number of committees they are invited fo attend, and of the quantity of paper to read, sofhe certainly dull and irrelevant. Obviously as few impediments as possible should be put in the way $\Phi$ f a doctor's work, but without some involvement the mechanics of his therapeutic community hinders his own work. There is scope for studies 50 see how doctors' part in administration may to kept to a minimum commensurate with full use $\varnothing \mathrm{f}$ their sapiential contribution. 
Industry has problems integrating its technologists into the life of the factory and they exhibit similar feelings about 'time-wasting' involvement in the overall management of the work. They easily become absorbed, to the exclusion of other commitments, in the development of their specialty. A managing director of a large electrical engineering works, impressed with the 'separatism' of his highly qualified technologists and concerned about the relationships between staff in his factory, thought that managers especially spent too much time 'working', and not enough 'talking'.

Hitherto consultants have enjoyed a wide measure of control of their work, a pre-requisite for clinical responsibility which is facilitated by the NHS, though this is not always appreciated by them. However, one man's control is another's constraint (2) and doctors may be slow in perceiving that if others are to have greater influence in their workplace, doctors may, in some respects, have a little less. Are there compensations? I suggest that these may be found in the team.

However erudite the consultant he cannot be master of all the knowledge and skill that is required for the comprehensive care of his patients, and this should not be a source of anxiety. The group of people who look after patients, whom we may loosely though reasonably call the 'team', contribute each their special knowledge and skill. Doctors may learn from nurses and technicians in renal dialysis units and the various kinds of intensive care units. The management of patients with ileostomies has been greatly improved by the special knowledge of nurses, and of the patients themselves. Doctors make use of the special knowledge gained by patients' associations of many kinds. The care of general ward patients has been improved and expedited by weekly joint discussions, that need to last no more than half an hour, between the firm's doctors and sisters, and the medical social worker, physiotherapist, occupational therapist and when possible, district nurse or health visitor. Such exercises, in which each is dependent to a degree on the work of others, are mutually supportive and offer learning opportunities for all engaged in them.

A practice designed to enhance team work and mutual support was introduced on two medical wards. (I I) Informal meetings lasting an hour took place every 2-4 weeks at which anyone who worked on the wards or for their patients, in any capacity, was welcomed. A wide variety of topics was spontaneously raised and discussed by many different members of staff, who came at different times. The meetings provided a forum for bringing all sorts of problems to light that would otherwise have remained hidden or festering. New energy was injected into solving long recognised problems. As a result there was at least the possibility that something might be done about them. Some of the meetings were used to resolve problems between the ward and other departments, by inviting someone, for example from the laundry, to come to them. It was concluded that if staff were to influence events in their workplace then managers were necessary as agents of elucidation and action, but could be effective as such only if they worked as coordinators and facilitators. The meetings were also used to discuss topics known to be a source of anxiety, for example the care of patients with self-poisoning, 'difficult' patients, young patients dying of cancer, and 'awkward' relatives. They provided an opportunity for sister and consultant to draw out the difficulties that inexperienced doctors and nurses may have in modifying their feelings about such clinical matters, particularly their hostility, at times overt, to overdose and 'difficult' patients.

Consultants can probably remain 'governors' of laboratories and radiology departments, two places where technicians want more say in their running, only by sensitive delegation of duties and responsibilities, and participative management. Clinical consultants can provide supportive compensations by regular meetings with service department consultants to discuss clinico-radiological or laboratory problems, and perhaps help with research. So these consultants may feel less isolated by being drawn partly into the 'ward team'.

To achieve a successful team that uses the increasing technological expertise available in the NHS to the best advantage of the patient is largely a matter of fostering good personal relations. The difficulties that may arise in multidisciplinary teams, especially when their members are not fully integrated, have been discussed. (12) Consultants have a key role in helping to create a supportive friendly milieu for welcoming and guiding discussions, drawing out contributions, engendering insight and understanding in themselves as well as others, asking the right questions, helping to get decisions and action, and making decisions within their own competence which includes the overall care of the patient. The patient needs someone, in the welter of technology, expertise and talk, to gather the threads together: in the words of the Lancet 'to see him through'. So the consultant is responsible for final decisions. But there is excitement and fulfilment in helping to tease out solutions to clinical and hospital problems from the combined contributions of different people working together. My experience is that when affairs are ordered in this way, with the goal recognised and accepted by all, no one wants to compete for the consultant's lot.

\section{Communications and medical audit}

Involvement in the Hospital Internal Communications Project (5) showed the importance of communications in drawing people in different jobs together and facilitating learning from experience. This project encouraged a questioning attitude 
towards traditional practices and promoted improved standards of service. (13)

A remarkable insight into the harm to relationships in hospitals resulting from lack of communication between consultants and non-professional staff, was provided by a recent note. (I4)

Studies on communications in medical audit $(15,16)$ including the use of problem oriented medical records, suggest that their refinement will help to control the quality of medical work and patient care. These studies have shown the value of autonomous learning by 'contributing to and profiting from the collective knowledge which is the basis of the best clinical practice'. Self-learning is a better educative process than forms of audit relying on sanctions, and is more acceptable.

The reluctance of the profession to accept the recommendations of the Davies Committee (17) on hospital complaints procedure is an expression of the dilemma in which doctors find themselves. Practitioners are offering a service to clients, and there is everything to be said for patient satisfaction. Complaints procedures may be the natural recourse of bureaucracies, and of some aggrieved patients or relatives who feel, like Albert's mother after the lion had swallowed her son, that 'someone has got to be summonsed'. However, procedures that overemphasise the making of complaints may be not only pernicious in encouraging gratuitous complaints, but also ineffective because of their essentially negative character. Professional defensiveness, not learning, may be the outcome. Patients and their relatives must, of course, be able easily to make representations when things go wrong, and know how to do it. Even so, suggestions should be invited on how to improve the service.

Prevention of dissatisfaction, more positive than trying to cure it, is best served by self-learning forms of (medical) audit. These entail learning how to restructure one's existing knowledge, and developing autonomous learning by self-questioning and self-discovery. Communication systems are integral to these developments, for learning is a social process and occurs best when real problems are tackled jointly with others also involved with them. (18, 19) The principal motive for achieving high standards of practice, including attitudinal change, is a value system closely related to client satisfaction. This needs to be emphasised at a time of doubt and disbelief in previously accepted values. However strong one's tenets there will be times of uncertainty, and then a start can be made to restore or construct a socially caring system of values, by asking: 'What am I trying to do? Am I succeeding? If not, why not? What can I do about it?'

\section{Professionalism}

Professions set up vigilant machinery to ensure high standards of knowledge and practice, but it must be remembered that the first purpose for this is to protect their clients and the machinery may not be sufficient to achieve this purpose. Profssionalism may even have dangers, as the philosopher A N Whitehead (20) has remarked. 'Effective knoivledge is professionalised knowledge, supported a restricted acquaintance with useful subjects subservient to it. This situation ... produces mind a groove. Each profession makes progress but is progress in its own groove. Now to be mentally a groove is to live in contemplating a given setoof abstractions. The groove prevents straying across the country and the abstraction abstracts from something to which no further attention is paid. But there is no groove of abstractions which is adequate for the comprehension of human life $\overline{\text {. . }}$ The leading intellects see this set of circumstanes, or that set; but not both sets together. . . . In short, the specialised functions of the community igre performed better and more progressively, but the generalised direction lacks vision. The progressiveness in details only adds to the danger produced by the feebleness of co-ordination'.

Like others professional people are concerned with their identity and the boundaries of their work, factors governing their sense of security. Whiple criticisms of professional work may lead to defensiveness, even aggression, in those performingoit, security should not be bought at the expense of client. We may expect of consultants, because of their training and knowledge, and the nature of their work, a heightened awareness of self, 面 of insight and perception of their own and oth $\overrightarrow{\mathrm{G}}$ s' attitudes. Joining an interdisciplinary group rmay lead to a sense of loss of professional identity which, however, is minimised by their continuing to wörk also in their own professional department. As horizontal communications between disciplifes and departments are developed - and they are now seen to be important in overcoming problems between them (2I) - people in the vertical struct ire of a professional hierarchy may come to feel threatened. (22) It is becoming a hallmark of the mature professional that he relates to wider contexts by getting outside his own patch. Professionalism, although based on the institutionalisatifin of knowledge and skills is now acquiring a new dimension, developing a series of relationsh $s$ between people and professional groups. (23) $\mathrm{\omega}$

The most effective professional is one who ․ㅏㅇ only knows how to do his job technically well has a high level of 'programmed knowledge' - Git one who also has the ability to ask the right questions, and to pursue the answers against odds. ( $18, \mathrm{IB})$ This attribute above all characterises the wise leader.

Consultants cannot escape these trends and developments. They are part of the changing cultire of their work. 'We need people who can create a面d sustain lively institutions, and one important qualification they need for this is the ability io function happily and effectively in at least two 
dimensions - to be lively and loyal members both of professions and of inter-professional groups - to have both vertical and horizontal loyalties - to make full use of professional frameworks, yet never to be slaves to them, always ready to modify, adapt or even discard them'. (23)

\section{Conclusion}

Most consultants do not see themselves in any sense as rulers, though they have enjoyed power, which now some feel is slipping from them. But 'consultant power' based on anything other than respect is an illusion, and respect for consultants is dependent not only upon a high level of programmed knowledge, but also on what they earn by modifying their attitudes and methods of practice, and by developing self-learning systems, and new relationships and loyalties. Leadership and wisdom lie in the art of asking the questions that will lead to solving problems and refining ideas for new initiatives.

The influence that professionals can wield is in direct proportion to the esteem in which their working community, their clients and society in general, hold them. By recognising that they cannot do their work properly without being part of a team or teams in some sense, they can derive new satisfactions from their role in making teams efficient for patient care.

\section{Acknowledgements}

The development of many of the ideas and practices mentioned in this paper would hardly have occurred without the supportive debates and commitment that are a feature of the work at the West Middlesex Hospital. Seminars and discussions at the King's Fund Centre also helped.

I am greatly indebted to all my colleagues, and to the staff generally, at the hospital; in particular to Dr J S Stewart, fellow consultant in our medical unit; to Mrs Eila Mohey, ward sister; to Ernest Steffens, District Administrator; and to Miss Janet Craig and Mrs Hazel Edwards of the King's Fund Centre; with all of whom many of the developments mentioned in this paper were brought about. The ideas of Professor $R$ W Revans have provided a constant stimulus to all of us.

\section{References}

(I) Coghill N F. Expectancy and realisation. Action Learning Trust, 45 Cardiff Road, Luton, Beds, 1978.

(2) Coghill N F. Development in the health serviceaction studies, participation and involvement. In: Revans R W, ed. Action learning in hospitals: diagnosis and therapy. London: McGraw Hill, 1976.

(3) Appeasement 1977 Style. British medical journal 1977; 4: 1619-1620.

(4) Dean M. The Guardian 1980; March I9: 8.

(5) Report from the West Middlesex Hospital. In: Revans $\mathbf{R} W$, ed. Hospitals: communication, choice and change. The hospital internal com- munications project seen from within. London: Tavistock Publications, 1972.

(6) Revans R W. The Project Method: Learning by Doing. In: Mailick S, ed. The making of the manager. The United Nations Institute for Training and Research (UNITAR), New York: Anchor Press/Doubleday, 1974.

(7) Stewart J S. Cogwheel: a physician's view of a local version. British medical journal 1969; 2 : 420-423.

(8) Revans J W. Standards for morale: cause and effect. Nuffield Provincial Hospitals Trust, London: Oxford University Press, I964 Reprinted in: Revans R W, ed. Action learning in hospitals: diagnosis and therapy. McGraw Hill, 1976.

(9) Bennett J R. Clinical responsibility I. Working papers. Primus inter pares? British medical journal 1977; 4: 1584-1585.

(I0) Coghill N F. Change and growth in hospitals. Lancet 1969; 2: 1058-ro6r.

(II) Coghill N F. Mohey E, Steffens E M, Stewart J S. Workers' participation and control in hospitals: the relevance of management. Second international conference on participation, workers' control and self-management, Paris, 1977. (Copies obtainable from the Action Learning Trust-see reference (I)).

(I2) Appleyard J, Maden J G. Multidisciplinary teams British medical journal 1979; 4: 1305-1307. And see subsequent correspondence, especially: Pastor T. British medical journal 1980; 280: 49. Dick B. British medical journal I980; 280: 49-50. Bevan J. et al. British medical journal 1980; 280 : 50.

(13) Revans, R W. Hospital performance and length of patient stay. London: King's Fund Centre, 76/269, 1976. Also available from the Action Learning Trust (see reference (I)).

(I4) Lester G S. Personal view. British medical journal 1980; $280: 476$.

(15) McColl I, Fernow L C. Mackie C, Rendall M. Communication as a method of medical audit. Lancet 1976; I: 134I-1344.

(16) Fernow L C, McColl I. The state of British medicine-II. Medical audit. Fournal of the Royal Society of Medicine 1978; 71 : 787-790.

(17) Davies Sir M. DHSS report of the committee on hospital complaints procedure. HMSO, 1973.

(18) Revans $R \mathbb{W}$. The response of the manager to change. Luton: Action Learning Trust, 1971.

(19) Revans R W. Management, productivity and risk. Luton: Action Learning Trust. 1980.

(20) Whitehead A. Science and the modern world. London: Cambridge University Press. 1933 Quoted in: Baker R J S, ed. Professionalism in the public services: a record of an interdisciplinary seminar, ref: PA/2/77, Department of Political Studies: Sheffield City Polytechnic, 1976.

(2I) Kirk C, Bennett A E. Management and advice at the grass roots. Lancet 1975; I: 1180.

(22) Montanez A. Mental health: collaboration and professional identity. In: Baker R J S, ed. Professionalism in the public services, a record of an interdisciplinary seminar, ref: PA/2/77, Department of Political Studies: Sheffield City Polytechnic, 1976.

(23) Baker R J S, Ibid.

\section{Author's note}

Offprints of this article are available direct from $\mathrm{Dr} N \mathrm{~F}$ Coghill, ${ }_{3} 8$ The Grove, Ealing, London W5 $3 \mathrm{SH}$ 